\title{
Transformações de memória e a paisagem urbana na Roma antiga: possibilidades interpretativas em longa duração
}

\author{
Transformations of memory and the urban landscape of ancient \\ Rome: some possibilities of long-term interpretation
}

MORCILLO, M. G.; RICHARDSON, J. H.; SANTANGELO, F. (Ed.).

Ruin or renewal? Places and the transformation of memory in the city of Rome. Roma: Quasar, 2016. 304 p.

Thiago de Almeida L. C. Pires*

Recebido em: 10/04/2018

Aprovado em: 13/05/2018

$\mathrm{F}$ ruto de uma conferência ocorrida em 2012, em Lampeter-Wales, a coletânea Ruin or renewal? Places and the transformation of memory in the city of Rome oferece importantes contribuições para pesquisadores que lidam com espaço, memória e religião na Roma antiga. Dividida entre um estudo introdutório e onze capítulos, a obra disponibiliza estudos que versam sobre diferentes marcos topográficos "em ruínas", mas que foram reutilizados, relidos e revitalizados pelos antigos romanos. O tema central dos estudos é como os monumentos, templos, marcos topográficos e seus contextos espaciais influenciaram e colaboraram na construção e no desenvolvimento da memória romana. Dessa forma, a memória cultural, longe de ser estática, tem seu aspecto de inventividade e reinvenção ressaltados. Muitas das narrativas de memória que chegaram até nós foram construídas tardiamente: as elites romanas sentiram a necessidade de explicar a sacralidade de determinados lugares, ações e práticas de culto, seus símbolos e sua localização. Para tanto, escritores, poetas e historiadores se debruçaram sobre o assunto do mos maiorum e redefiniram os conhecimentos dos 'caminhos dos antepassados', remodelando tradições, ou seja, criaram narrativas para explicar a razão da sacralidade desses locais. Esses homens

\footnotetext{
* Doutorando pelo programa de Pós-Graduação em História da Universidade Federal do Estado do Rio de Janeiro (UNIRIO) sob orientação da Profa. Dra. Claudia Beltrão da Rosa. Bolsista da Coordenação de Aperfeiçoamento de Pessoal de Nível Superior (Capes).
} 
serão conhecidos pela historiografia moderna como antiquários (MOATTI, 2008, p. 148). Fenômeno cultural de longa duração, o movimento antiquarista começou a tomar forma na República média e atingiu seu auge no Principado. As narrativas apresentadas como 'resgatadas' pelos antiquários dificilmente existiram: diversos elementos novos foram apresentados ao público como se fossem antigos, ancestrais. Os antiquários retratavam símbolos, objetos ou localidades como antiquíssimos, mesmo sendo relativamente novos na cultura romana. Nesses casos, houve uma fusão de elementos antigos e elementos novos, suposições dos antiquários sobre como os eventos ancestrais teriam ocorrido.

Os antiquários, contudo, não eram guiados apenas pela imaginação, mas pelos indícios dos espaços, monumentos, tradições orais e pelas ruínas espalhadas pelos diversos espaços de Roma. Em geral, os pesquisadores modernos buscam em textos escritos explicações sobre determinados pontos topográficos. Ruin or Renewal? nos auxilia no sentido inverso: o espaço, as estátuas e a monumentalização próxima podem também informar e oferecer indícios de significado para a memória coletiva religiosa e cultural. Não há preponderância de um tipo de documentação sobre o outro, mas uma sinergia entre mídias que auxilia o pesquisador moderno a compreender como os antigos romanos entendiam, reliam, reinterpretavam e renovavam suas "ruínas". Assim, a paisagem urbana na Roma antiga não era um simples cenário: em uma sociedade na qual a maioria das pessoas não tinha acesso a livros e não sabia ler e escrever, os espaços, monumentos e pontos topográficos tinham funções didáticas, ensinavam ao transeunte a história de seu povo, suas conquistas e auxiliavam a formar sua identidade. Os autores de Ruin or Renewal? aqui são enfáticos: não eram apenas os textos escritos que forneciam significados aos espaços, mas os espaços, seus monumentos e suas narrativas orais também forneciam indícios na criação da memória. Nesse sentido, a obra é uma contribuição e desenvolvimento dos estudos de Hölkeskamp (2006) e Peter Wiseman (2014) sobre a interdependência semiótica entre diversas mídias, que "carregavam" simbolicamente espaços com memórias e auxiliavam na construção da identidade romana.

No primeiro capítulo, "Monuments of the regal period and the beginnings of the Republic: the ambiguity of realia", Dominique Briquel problematiza o significado imputado pelos antiquários a diversas estátuas heroicas situadas no Fórum, especialmente aquelas identificadas como sendo os últimos reis de Roma. $O$ autor contesta tal visão, salientando que tais estátuas já eram antigas na própria Roma monárquica e eram provavelmente estátuas de culto. Assim, os romanos republicanos reinterpretaram aquelas estátuas como figurações dos antigos reis.

No capítulo intitulado "The statue of Marsyas", Federico Santangelo analisa a tradicional estátua do sátiro Marsyas esfolado. A estátua não sobreviveu até hoje, mas 
existem réplicas, moedas e descrições em textos antigos. A longevidade da estátua de Marsyas conferiu à sua representação significados antagônicos: desafiador da ira de Apolo ou herói da liberdade e da emancipação plebeia? Santangelo recorre a estátuas similares, a representações em moedas, à linhagem genealógica de famílias nobres, ao uso do espaço no qual ela se situava, e outros elementos para tentar se aproximar de como um(a) romano(a) interpretava aquela estátua. Longe de ambicionar um resultado conclusivo, o estudo de Santangelo chama a nossa atenção para as possibilidades polissêmicas da arte.

Em "Virum mihi, Camena, insece: the cult of the Camenae", James H. Richardson percorre o caminho das origens da poesia em Roma para compreender o papel das Camenae, deusas similares às musas gregas, que incitavam ao canto e à memória. Com esse intento, o autor explora a região ao redor da Porta Capena, na qual existia o local de culto e um bosque dedicados a elas. O autor defende que primitivamente esse lugar teria sido um local de canto de vitórias militares, no qual os chefes vitoriosos depunham suas armas e declamavam suas façanhas aos senadores. O passar do tempo fez com que a Porta Capena perdesse sua conotação militar para outros locais, mas as Camenae continuaram vinculadas ao canto profético e à memória militar do lugar desvaneceu.

Don Miller, em "For country, god, or self? Religious dedications and the construction of public image in Republican Rome", investiga a construção do primeiro arco de triunfo de Roma: o de Cornélio Cipião Africano, em celebração às suas vitórias na Segunda Guerra Púnica. Por que sua construção no ano 190? Quais símbolos o monumento ostentava e quais seus possíveis significados? Miller esclarece, com base nessas perguntas, que o arco de Cipião não era apenas um gatilho de memória de vitórias, mas também uma oferta religiosa aos deuses patronos, um presente cívico aos compatriotas e mais um adorno para a paisagem urbana.

No quinto capítulo, "Placing the hasta in the forum: Cicero and the topographic symbolism of patrimonial sales", Marta García Morcillo averigua como o ritual "sob a lança" (sub hasta) sofreu alterações ao longo do tempo. Esse ritual determinava a venda em leilões de itens conquistados dos inimigos, mas Cícero, em seus escritos, denuncia que o ritual foi corrompido para a venda de terras de cidadãos romanos em épocas de proscrição. Um dos aspectos centrais do texto de Morcillo é como Cícero explora os índices topográficos do Fórum: o espaço não é pano de fundo do discurso, mas o argumento de Cícero é construído a partir da observação e uso dos espaços e monumentos do Fórum.

O capítulo "The Augustan 'rebuilding' of the capitolium", de Alexander Thein, trata de um dos espaços sagrados mais tradicionais de Roma: o Capitólio. O mérito de Thein é ir na contramão de uma historiografia que costuma dar pouca importância às intervenções augustanas na colina: o princeps precisou ser discreto e cauteloso ali por 
ser uma topografia muito carregada de memória. $\mathrm{O}$ autor analisa as $R G D A$, as reformas augustanas e a numismática para salientar que o Capitólio não foi negligenciado por Augusto, mas teve suas características "originais" reforçadas por meio de ornamentações e sinergias com outras áreas de Roma.

No capítulo "The temple dedicated to Jupiter Feretrius on the Capitoline Hill", Lily Withycombe se debruça sobre questões relacionadas a um dos templos mais antigos de Roma: o templo de Júpiter Feretrius. A tradição relata que o templo foi fundado por Rômulo e nele estavam depositados as spolia opima, troféus de guerra tomados de um chefe inimigo num combate singular. A autora percorre a documentação sobre o templo, sua possível aparência, as simbologias relacionadas e como as memórias associadas a ele sofreram alterações para demonstrar como o templo mudou de função com a realocação das spolia opima para o Fórum de Augusto.

Em "Memory, nostalgia and the Roman home", Lucy Jones examina o papel da domus aristocrática no cenário urbano de Roma. A casa urbana aqui figura como reservatório mnemônico de ancestralidade, que abrigou durante gerações uma família tradicional e trazia consigo recordações dos grandes exempla. Contudo, a memória de uma domus não era permanente: o novo morador poderia degenerar sua imagem por intermédio de atos desonrosos e infâmia. Além disso, a autora traz outra questão: como um novus homo agia na política sem uma casa urbana ancestral carregada de memórias?

John Patterson, em "Imperial Rome and the demise of the republican nobility", indaga sobre o papel da aristocracia e das tradicionais famílias republicanas no início do Principado e como sobreviveram, ou não, os monumentos que ostentavam e rememoravam os feitos dessas famílias. O autor observa como alguns monumentos ligados a essa nobilitas caíram em desuso por causa da extinção ou decadência da família, enquanto outros foram revitalizados e cooptados pelo princeps, tendo sua memória "original" reformulada.

No décimo capítulo, "Memory and epigraphy. The pauper at Rome in the first century AD", Maria Letizia Caldelli e Cecilia Ricci exploram um campo pouco desbravado por pesquisadores: foram bastante estudadas epigrafias de ricos nobres e as epigrafias de escravos. As autoras fogem dos dois polos e buscam as memórias dos pauperes, a "classe média" romana, principalmente durante o Principado. As inscrições e epitáfios desses pauperes indicam que tipos de memórias esses indivíduos, ou famílias, desejavam ostentar publicamente para a eternidade.

Já no último capítulo, "Past and present in the Late Imperial epigraphy of the city of Rome", Silvia Orlandi trabalha com a Antiguidade Tardia romana e como essa sociedade lidou com tentativas de restauração de monumentos e espaços dilapidados e em ruínas. 
Para tanto, a pesquisadora recorre aos estudos epigráficos para investigar como a ideia de Roma como Cidade Eterna precisou ser proclamada em palavras, já que o aspecto urbano decadente indicava o contrário. O aspecto principal do estudo de Orlandi é como a epigrafia dessa época refletiu o jogo passado-presente: mesmo uma cidade repleta de ruínas e decadente poderia evocar sua "beleza eterna".

O livro é finalizado com dois úteis indices: um index geral e outro index locorum, subdividido em documentação literária e documentação epigráfica. O livro não traz uma bibliografia geral, pois cada capítulo tem a sua própria.

Em conclusão, a obra possui dois grandes méritos. 1) quase todos os autores lidam com monumentos, estátuas e espaços que fisicamente não sobreviveram, mas pela análise documental inferem informações preciosas; 2) os estudos documentais foram realizados em lapsos temporais de longa duração, o que resultou em "variações de memória" em determinados marcos topográficos. Assim, o leitor é alertado que não deve tomar uma interpretação como unívoca: as interpretações foram e são produzidas em momentos determinados e por autores particulares, ainda que coletivos. As obras de arte e monumentais em Roma majoritariamente eram abertas a diversas interpretações, polissêmicas, e por isso nenhum resultado que se pretenda conclusivo é realmente conclusivo. Mais do que trazer respostas, Ruin or renewal? provoca no leitor mais perguntas e instiga a pesquisa sobre o profícuo campo de estudo dos espaços e da memória na Roma antiga.

\section{Referências}

HÖLKESKAMP, K. History and collective memory in the middle Republic. In.: ROSENSTEIN, N.; MORSTEIN-MARX, R. (Ed.). A companion to the Roman Republic. Oxford: Blackwell, 2006.

MOATTI, C. La razón de Roma. Madrid: Antonio Machado Libros, 2008.

MORCILLO, M. G.; RICHARDSON, J. H.; SANTANGELO, F. (Ed.). Ruin or renewal? Places and the transformation of memory in the city of Rome. Roma: Quasar, 2016.

WISEMAN, T. Popular Memory. In.: GALINKSY, K. (Ed.). Memoria romana: memory in Rome and Rome in memory. Ann Arbor: University of Michigan Press, 2014. 